\title{
Ectopic cartilage in subglottic stenosis: hamartoma or reaction to trauma?
}

\author{
F.C.P.M. Adriaansen ${ }^{1}$, L.J. Hoeve ${ }^{2}$, H.L. Verwoerd-Verhoef ${ }^{1}$, \\ R.O. van der Heul ${ }^{2}$ and C.D.A. Verwoerd ${ }^{1}$ \\ Department of ${ }^{1}$ Otorhinolaryngology and ${ }^{2}$ Clinical Pathology, Erasmus University Rotterdam. \\ Rotterdam (The Netherlands) \\ (Received 14 March 1991) \\ (Revised version received 28 June 1991) \\ (Acceptcd 5 July 1991)
}

Key words: Ectopic cartilage; Subglottis stenosis; Hamartoma

\begin{abstract}
In an experimental study in growing rabbits an endolaryngeal injury to the subglottis resulted in the development of a stenosis due to the formation of scar tissue containing ectopic cartilage. For comparison, biopsies taken from the subglottic stenosis in 8 children were studied histologically. In 6 cases ectopic cartilage was observed; all patients had a history of endotracheal intubation. In 3 children the diagnosis hamartoma was made. In the remaining 3 cases the formation of ectopic cartilage might have been a direct reaction to the endolaryngeal intubation. The observations suggest that the formation of ectopic cartilage in acquired subglottic stenosis is not always due to a developmental aberration such as a hamartoma.
\end{abstract}

\section{Introduction}

Endotracheal intubation can lead to the formation of a subglottic stenosis. Especially in infants and children the treatment of acquired stenosis is a difficult clinical problem. The causes for failure of therapy are still poorly understood. To investigate basic characteristics in the development of a subglottic stenosis an experimental study in growing rabbits was performed. The morphometric results illustrated specific patterns of disturbed development of the cricoid ring after

Correspondence: F.C.P.M. Adriaansen, Department of Otorhinolaryngology, Erasmus University Rotterdam, Dr. Molewaterplein 50, 3015 GE Rotterdam, The Netherlands. 
trauma [1]. The histology showed the formation of ectopic cartilage in the subepithelial scar tissue and thickening of the cricoid cartilage at some sites [2,3].

From 1985 to 1990 a laryngofissure was performed in 12 children for repair of chronic subglottic stenosis. In all patients repeated endotracheal intubations had been necessary for ventilatory support. In 8 cases a biopsy of the stenosis was taken. In this paper the histology of the biopsies will be compared with data obtained from the animal experiments.

\section{Materials and Methods}

Twenty-one female New Zealand White rabbits were used. At the age of 4 weeks the subglottic airway was damaged circumferentially using a cutting burr as previously described [1]. In 10 animals the injury was restricted to the epithelium and subepithelial layer. In the remaining specimens the perichondrium and the innermost layer of the cricoid cartilage were damaged as well. At the adult stage of 24 weeks the animals were sacrificed. The subglottic part of the larynx was excised and processed histologically; $5-\mu \mathrm{m}$ transverse sections were prepared and stained with hematoxylin-azophloxin.

From 8 patients tissue obstructing the laryngeal airway was excised at different sites in the subglottic region (see Results). After histologic processing $5-\mu \mathrm{m}$ sections were obtained and stained with hematoxylin-azophloxin.

\section{Results}

Experimental animals $(n=20)$

A detailed histologic description has been reported previously [2,3]. The data will be summarized. The subglottic airway is lined with normal respiratory epithelium. Glands as well as the tunica elastica are missing. The regenerated subepithelial layer consists of fibrous scar tissue, fatty tissue and blood vessels. Regardless of the depth of the endolaryngeal trauma ectopic cartilage is present in all but one specimen (Fig. 1). The newly formed cartilage is distributed randomly in the scar tissue and resembles either a hyaline or a fibro-cartilaginous type (Fig. 2). The cricoid cartilage and perichondrium display a normal adult aspect.

Patients $(n=8)$

In 6 out of 8 biopsies ectopic cartilage was present. The histology of this sub-group shows:

(1) D.R.: dense fibrous tissue with leucocyte infiltration and a fibro-cartilaginous type of cartilage (Fig. 3); polarisation shows the collagen fibres to continue their course from the cartilage into the surrounding fibrous tissue without an intervening perichondrial layer (Fig. 4).

(2) A.T.: fibrous tissue with areas of a fibro-cartilaginous type of cartilage and secondarily formed bone.

(3) A.B.: fibrous tissue with a hyaline and fibrocartilaginous type of cartilage; also areas of fatty tissue and secondarily formed bone containing marrow (Fig. 5). 


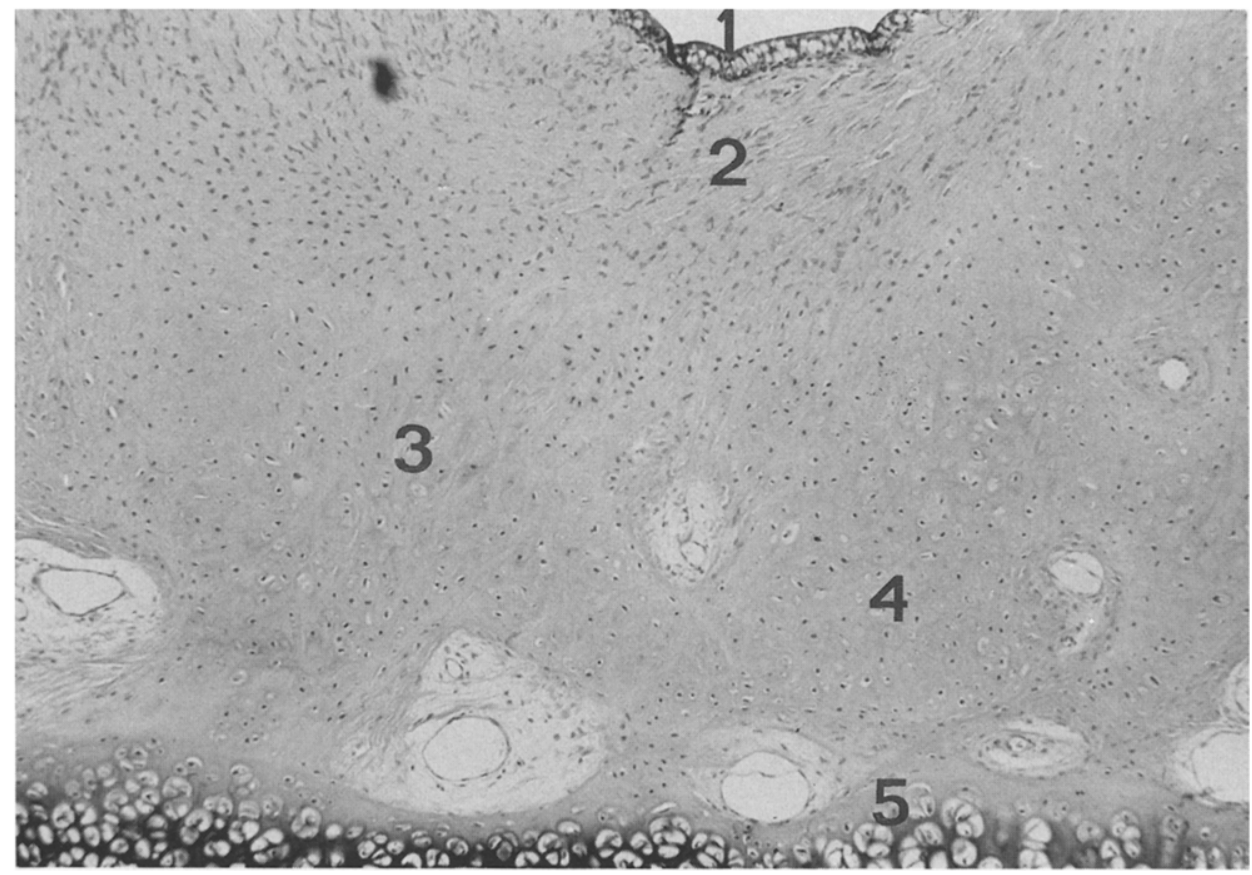

Fig. 1. Experimental animal: part of the subglottis 20 weeks after endolaryngeal trauma: regenerated epithelium (1), fibrous tissue (2) in thickened subepithelial layer with areas of ectopic cartilage of hyaline (3) and of fibro-cartilaginous type (4) in contact with cricoid (5). (haematoxylin-azophloxin, magn. $25 \times)$

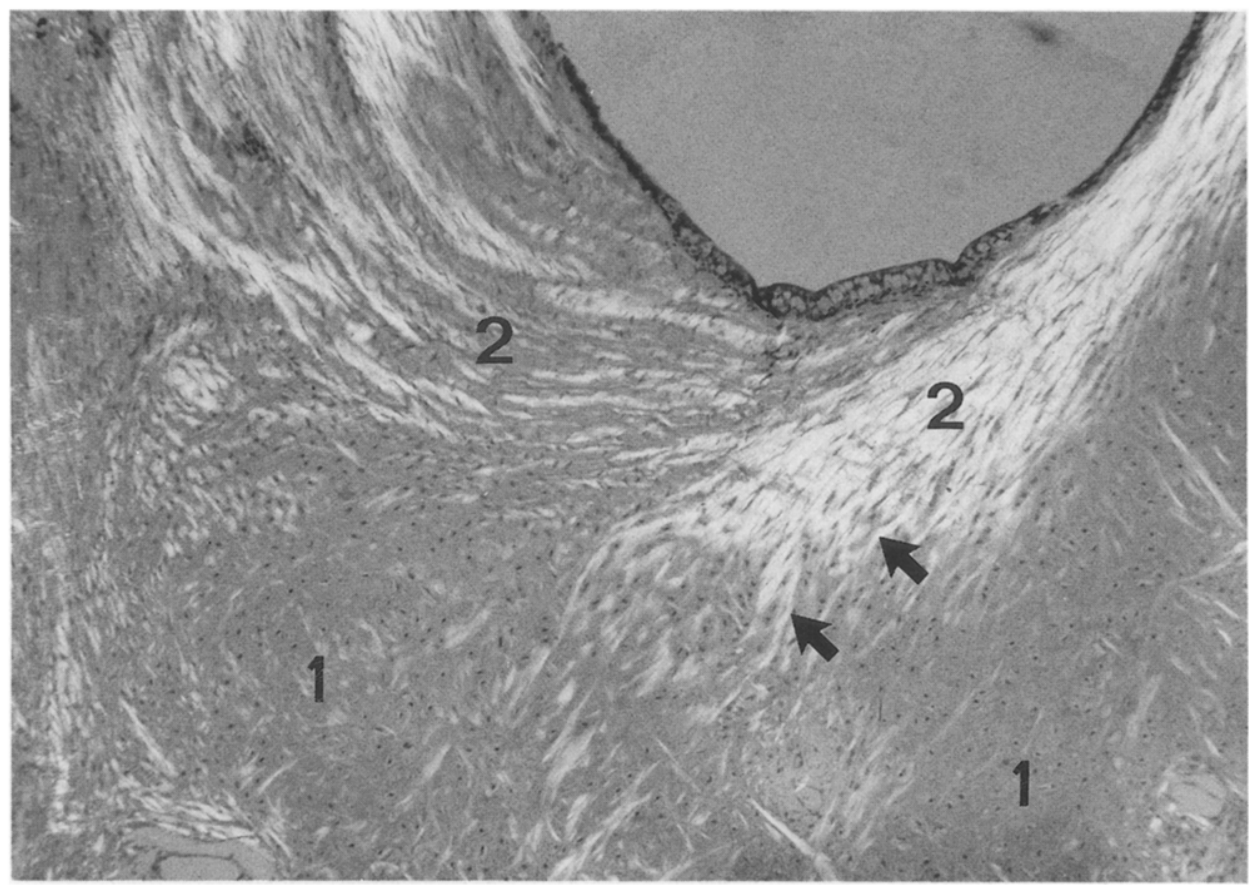

Fig. 2. Experimental animal: collagen fibres (arrows) continue from ectopic cartilage of fibrocartilaginous type (1) into fibrous tissue (2). (haematoxylin-azophloxin (birefringent light), magn. $40 \times$ ) 


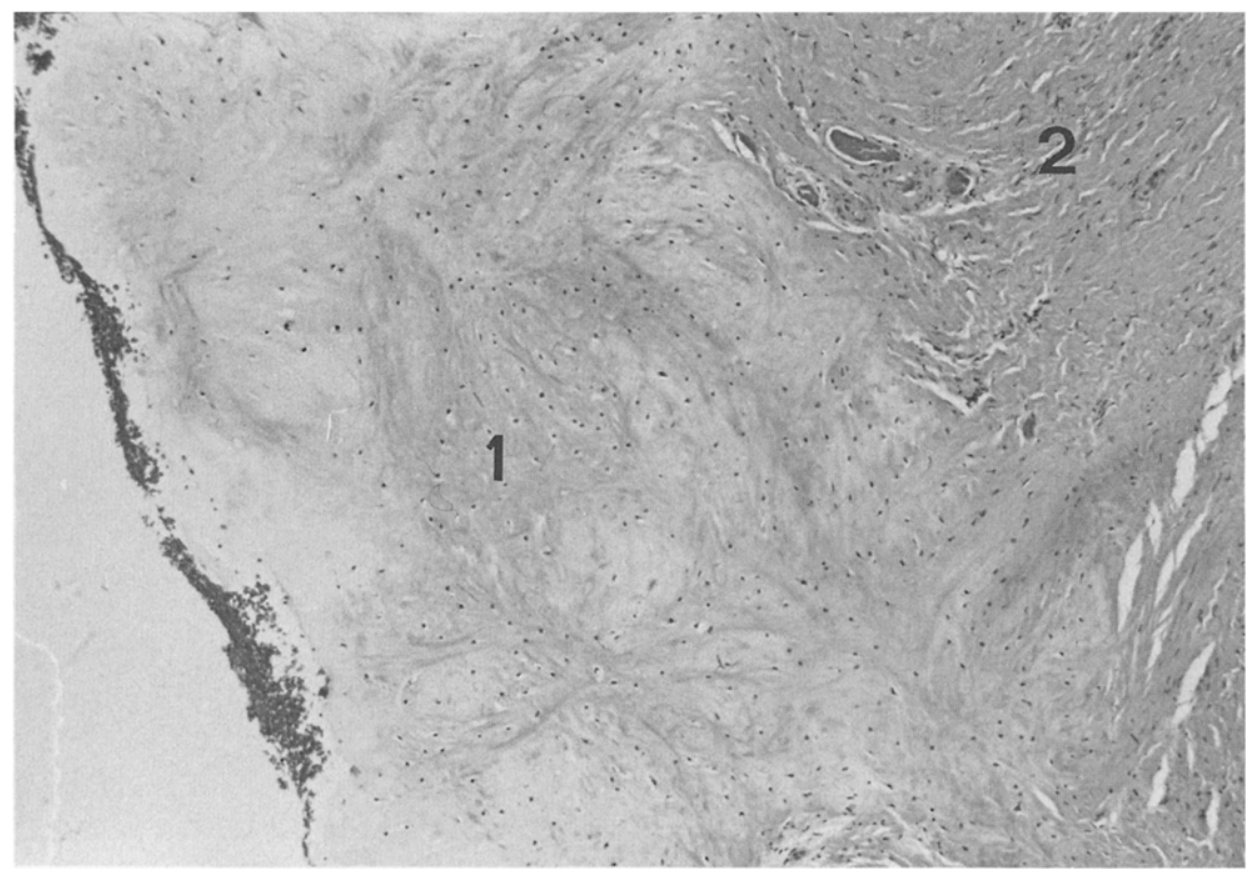

Fig. 3. Human specimen (D.R.): dense fibrous tissue (2) and ectopic cartilage of fibro-cartilaginous type (1). (haematoxyliri-azophloxin, magn. $40 \times$ )

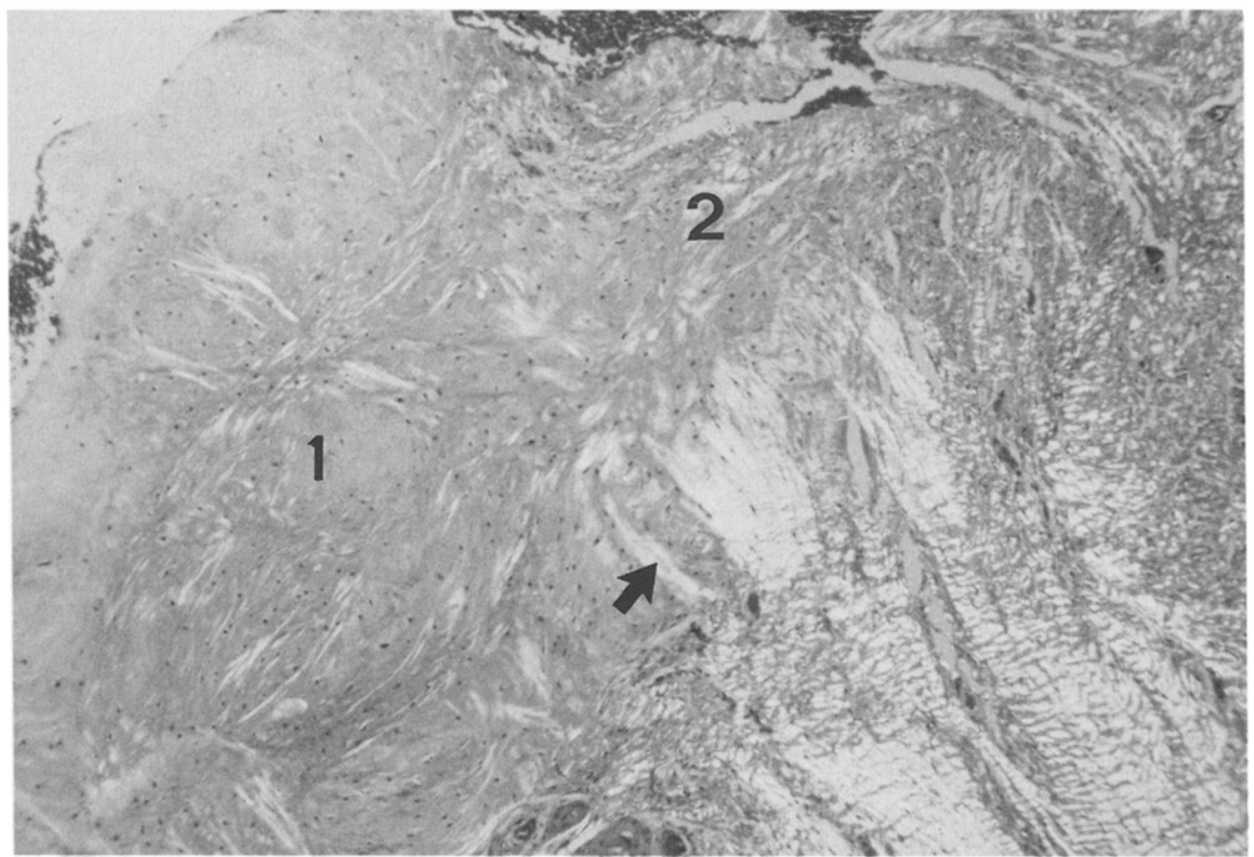

Fig. 4. Human specimen (D.R.): fibro-cartilaginous type of ectopic cartilage (1); collagen fibres (arrow) continue into fibrous tissue (2) without perichondrial layer. (haematoxylin-azophloxin (birefringent light), magn. $40 \times$ ) 


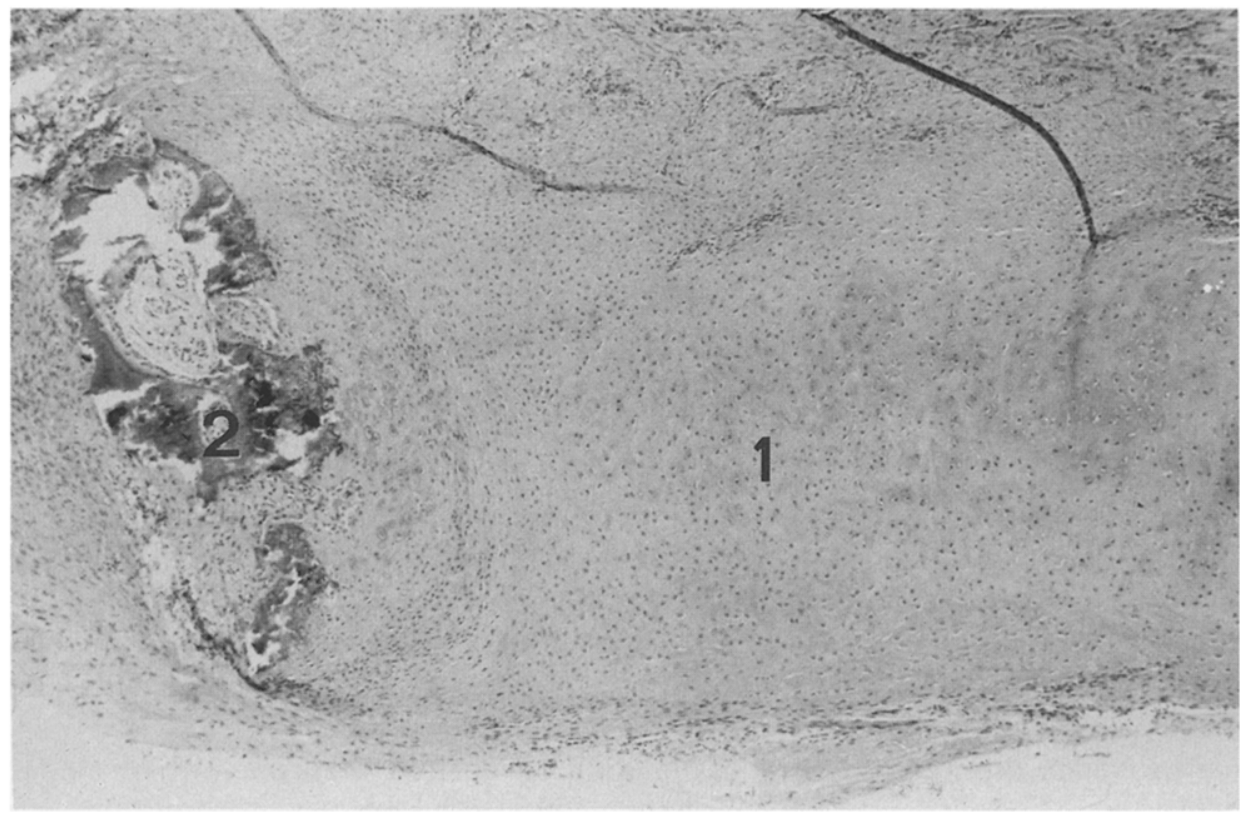

Fig. 5. Human specimen (A.S.): ectopic cartilage (1) of hyaline type with secondarily formed bone (2). (haematoxylin-azophloxin, magn. 100x)

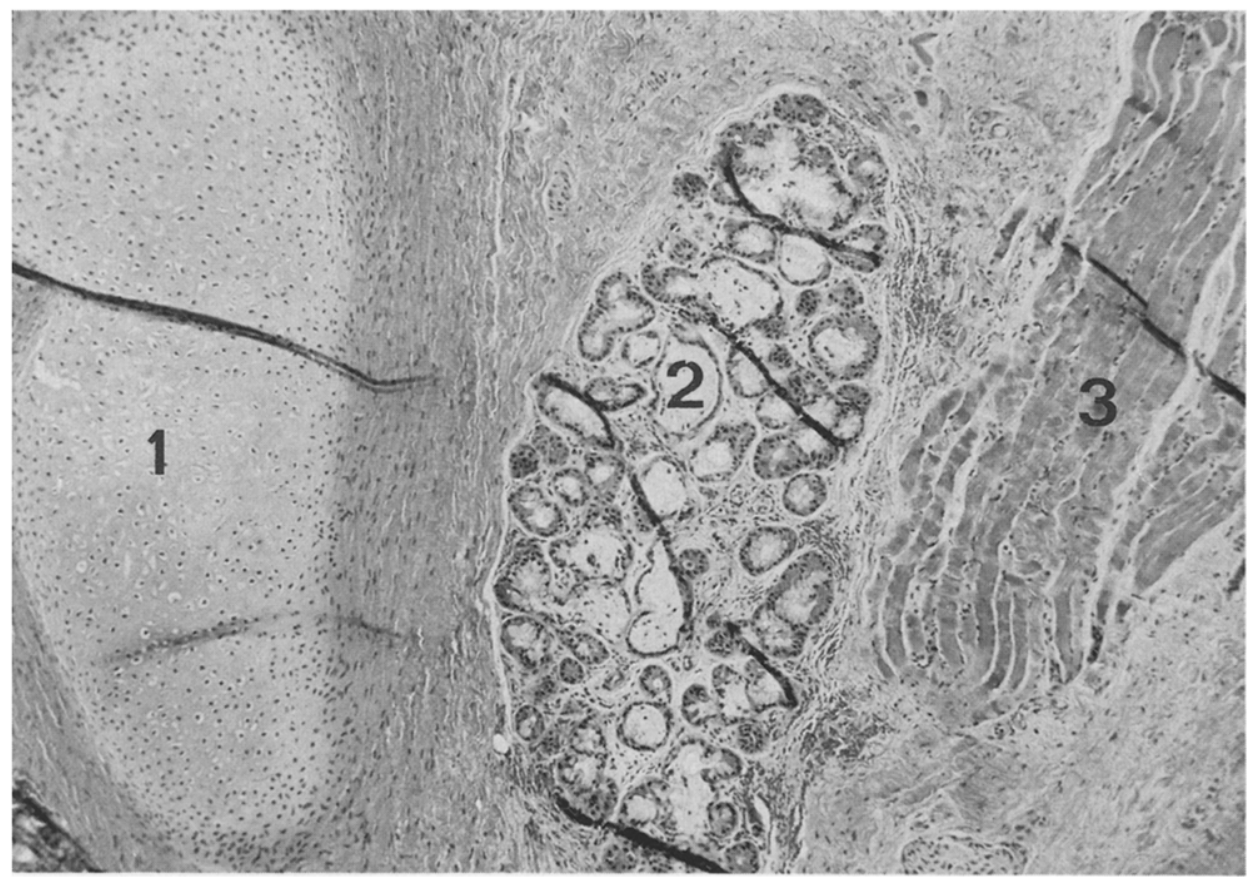

Fig. 6. Human specimen (G.K.): ectopic cartilage of hyaline type (1), glands (2) and muscle tissue (3). (haematoxylin-azophloxin, magn. $40 \times$ ) 
(4) G.K.: hyaline cartilage surrounded by fibrous tissue, orderly arranged muscle tissue and glands (Fig. 6).

(5) G.O.: fibrous tissue, a hyaline type of cartilage and muscle tissue; also some nervous tissue is present.

(6) J.P.: fibrous tissue with leucocyte infiltration and both a hyaline and fibrocartilaginous type of cartilage, muscle tissue, nerve trunks and glands.

\section{Discussion}

The experimental study in growing rabbits showed the chondroneogenesis in the larynx to be the product of endolaryngeal trauma [2,3]. To date the formation of ectopic cartilage after injury has not been reported in cases of acquired subglottic stenosis in infants and children. However, 'thickening' of the cricoid has been observed macroscopically in pediatric cases of subglottic airway narrowing after endotracheal intubation [4-6].

In humans differentiation of granulation tissue into cartilage with secondary formation of bone is a well-known phenomenon in the process of wound repair in muscle tissue (myositis ossificans) [7]; the formation of ectopic cartilage and bone is a reaction to injury and should not be considered as a hamartoma. A hamartoma is defined as a developmental aberration in which the tissues of a particular part of the body are all present, but arranged randomly with excess of one or more of the components [8].

In 3 of the patients (D.R., A.T., A.B.) the cartilage was the only ectopic tissue amidst the fibrous tissue and could, therefore, not be classified as a hamartoma of the larynx. The fibrous matrix of the cartilage merges into the surrounding fibrous tissue indicating the chondroneogenesis to occur within the scar formation (Fig. 4). In these patients the formation of ectopic cartilage might have been a direct reaction to the intubation injury.

The biopsies of 3 other patients (G.K., G.O., J.P.) contain cartilage apart from muscle tissue, nerves and glands. In two of these cases (G.K. and G.O.) the biopsies were taken from the lateral or posterior subglottic area, so the lateral cricoid arytenoid muscle might have been included in the biopsy of the first patient. In one case (J.P.) the biopsy was taken from an obstructing mass based on the laryngeal side of the epiglottis. In the normal anatomy no muscle is situated in this region, hence the diagnosis hamartoma seems to be justified.

The results of this comparative histologic study suggest that: (1) the formation of ectopic cartilage is not always caused by an aberrant development such as in a hamartoma; if ectopic cartilage is found in the larynx, suspicion of a post-traumatic lesion should be raised; and (2) the presence of ectopic cartilage in cases of acquired subglottic stenosis in infants and children might be a cause for therapy failure. 


\section{References}

1 Adriaansen, F.C.P.M., Verwoerd-Verhoef, H.L., Van der Heul, R.O. and Verwoerd, C.D.A., A morphometric study of the growth of the subglottis after endolaryngeal trauma, Int. J. Pediat. Otorhinolaryngol., 12 (1986) 217-226.

2 Adriaansen, F.C.P.M., Verwoerd-Verhoef, H.L., Van der Heul, R.O. and Verwoerd, C.D.A., A histologic study of the growth of the subglottis after endolaryngeal trauma, Int. J. Pediat. Otorhinolaryngol., 12 (1986) 205-215.

3 Adriaansen, F.C.P.M., Verwoerd-Verhoef, H.L., Van der Heul, R.O. and Verwoerd, C.D.A., Differential effects of endolaryngeal trauma upon the growth of the subglottis, Int. J. Pediat. Otorhinolaryngol., 15 (1988) 163-171.

4 Cotton, R.T. and Myer, Ch.M., Contemporary surgical management of laryngeal stenosis in children, Am. J. Otolaryngol., 5 (1984) 360-368.

5 Crysdale, W.S., Extended laryngofissure in the management of subglottic stenosis in the young: a preliminary report, J. Otolaryngol., 5 (1976) 479-486.

6 Grahne, B., Operative treatment of severe chronic traumatic laryngeal stenosis in infants up to 3 years old, Acta Otolaryngol., 72 (1971) 134-137.

7 Robbins, S.L. and Cotran, R.S., Pathologic Basis of Disease, 2nd edn. Saunders, Philadelphia, 1979.

8 Walter, J.B. and Israel, M.S., General Pathology, 5th edn., Churchill Livingstone, Edinburgh, 1979. 